\title{
Wavelength dependence of the magnetic resolution of the magneto-optical near-field scanning tunneling microscope
}

\section{Citation for published version (APA):}

Schad, R., Jordan, S. M., Stoelinga, M. J. P., Prins, M. W. J., Groeneveld, R. H. M., Kempen, van, H., \& Kesteren, van, H. W. (1998). Wavelength dependence of the magnetic resolution of the magneto-optical nearfield scanning tunneling microscope. Applied Physics Letters, 73(18), 2669-2671.

https://doi.org/10.1063/1.122548

DOI:

10.1063/1.122548

Document status and date:

Published: 01/01/1998

\section{Document Version:}

Publisher's PDF, also known as Version of Record (includes final page, issue and volume numbers)

\section{Please check the document version of this publication:}

- A submitted manuscript is the version of the article upon submission and before peer-review. There can be important differences between the submitted version and the official published version of record. People interested in the research are advised to contact the author for the final version of the publication, or visit the $\mathrm{DOI}$ to the publisher's website.

- The final author version and the galley proof are versions of the publication after peer review.

- The final published version features the final layout of the paper including the volume, issue and page numbers.

Link to publication

\section{General rights}

Copyright and moral rights for the publications made accessible in the public portal are retained by the authors and/or other copyright owners and it is a condition of accessing publications that users recognise and abide by the legal requirements associated with these rights.

- Users may download and print one copy of any publication from the public portal for the purpose of private study or research.

- You may not further distribute the material or use it for any profit-making activity or commercial gain

- You may freely distribute the URL identifying the publication in the public portal.

If the publication is distributed under the terms of Article 25fa of the Dutch Copyright Act, indicated by the "Taverne" license above, please follow below link for the End User Agreement:

www.tue.nl/taverne

Take down policy

If you believe that this document breaches copyright please contact us at:

openaccess@tue.nl

providing details and we will investigate your claim. 


\title{
Wavelength dependence of the magnetic resolution of the magneto-optical near-field scanning tunneling microscope
}

\author{
R. Schad, S. M. Jordan, M. J. P. Stoelinga, M. W. J. Prins, R. H. M. Groeneveld, \\ and $\mathrm{H}$. van Kempen ${ }^{\mathrm{a}}$ \\ Research Institute for Materials, University of Nijmegen, Toernooiveld 1, NL-6525 ED Nijmegen, \\ The Netherlands \\ H. W. van Kesteren \\ Philips Research Laboratories, Prof. Holstlaan 4, NL-5656 AA Eindhoven, The Netherlands
}

(Received 4 June 1998; accepted for publication 3 September 1998)

A magneto-optical near-field scanning tunneling microscope is used to image the prewritten magnetic domain structure of a Pt/Co multilayer. A semiconducting tip acts as a local photodetector to measure the magnetic circular dichroism signal coming from the magnetic sample. The resolution of the magnetic imaging is given by the photoelectrically active volume of the tip. Reduction of the laser light wavelength resulted in a factor of 4 improvement of the magnetic resolution. Based on a sound and applicable definition we estimate the resolution to be $(60 \pm 35) \mathrm{nm}$ for a wavelength of $532 \mathrm{~nm}$. () 1998 American Institute of Physics. [S0003-6951(98)04044-3]

Magnetic materials are essential ingredients of many modern industrial products. The purposeful further development of such systems requires a detailed understanding of their magnetic properties, in particular, the dependence on their dimensions. The central issue is the visualization of the magnetic fine structure, the magnetic domains. Their shape and behavior are the key to understanding of the overall magnetic properties of the systems. Due to the continuous size reduction of devices and bit sizes in magnetic data storage media, suitable high-resolution magnetic imaging techniques are required for routine investigation. The ideal microscope would provide sufficient resolution under ambient conditions, in external magnetic fields and without magnetic interaction with the sample. Currently existing techniques do not fulfill all requirements having either insufficient resolution (Kerr microscopy), requiring inconvenient vacuum conditions (Lorentz electron microscopy, scanning electron microscopy with polarization analysis) or having unacceptable magnetic probe-sample interactions (magnetic force microscopy). ${ }^{1}$ Magneto-optical scanning near-field microscopy is a promising alternative, ${ }^{2}$ however, still suffers from substantial technical problems when using glass-fiber optics.

In our near-field microscope, the magneto-optically obtained magnetic information is detected using a semiconducting (GaAs) tip acting as a local photodiode. ${ }^{3}$ This semiconductor tip is part of a regular scanning tunneling microscope (STM). The advantages of this magneto-optical near-field (MONF) STM are the absence of magnetic tip-sample interactions and the fact that it can operate in external magnetic fields and under ambient conditions. In addition, it gives the surface structure with the usual STM resolution. In an earlier paper $^{4}$ we reported an estimated resolution of $250 \mathrm{~nm}$. There we discussed several ways to improve the resolution. In this letter, we describe one of those methods: a reduction of the optical penetration depth in the semiconductor tip. ${ }^{5} \mathrm{~A}$ factor

${ }^{a)}$ Corresponding author. Electronic mail: hvk@sci.kun.nl
4 improvement of the magnetic resolution is obtained by a reduction of the wavelength of the laser light used. Based on a sound and applicable definition we estimate the resolution to be $(60 \pm 35) \mathrm{nm}$ for a wavelength of $532 \mathrm{~nm}$.

The experiments were performed using a home-built STM at ambient temperature and pressure. The tips were prepared by cleaving GaAs(001) wafers ( $p$ type of $10^{17} \mathrm{~cm}^{-3}$ doping density) along $\langle 110\rangle$ directions, forming a corner bounded by these planes. Inspection by scanning electron microscopy (SEM) and STM showed that cleavage produced well-defined corners with tip apex radii smaller than $100 \mathrm{~nm}$. The sample was a $\mathrm{Co} / \mathrm{Pt}$ superlattice with perpendicular easy magnetization axis consisting of a $6 \AA \mathrm{Pt}$ base layer and 20 pairs of $3.5 \AA \mathrm{Co} / 6 \AA \mathrm{Pt}$ layers evaporated on a glass substrate. The sample was homogeneously magnetized except for rows of thermomagnetically written bits of opposite magnetization. The bits had a nominal diameter of $0.8 \mu \mathrm{m}$ and were spaced $2.0 \mu \mathrm{m}$ apart within the rows. The rows were separated by a distance of $2-3 \mu \mathrm{m}$.

Essentially, the microscope's working principle consists of two parts, first, the magneto-optical probing of the magnetic properties using polarized light and second, the detection of the resulting light intensity variations by a semiconductor STM tip. In detail, circularly polarized laser light (20 $\mu \mathrm{m}$ focus diameter) illuminates the transparent magnetic sample from the back. Upon passing through the magnetic sample the light intensity is attenuated. This attenuation depends on the magnetization direction relative to the polarization of the light, an effect called magnetic circular dichroism (MCD). Thus, the light intensity after passing through the sample is dependent upon the magnetic information within the sample. The light intensity is detected locally using a photosensitive semiconducting GaAs tip where a number of electron-hole pairs proportional to the intensity is generated. The electrons are accelerated towards the apex of the tip by the electric field of the tip band bending. The tip is in about $1 \mathrm{~nm}$ distance to the sample surface forming a tunnel contact in form of a STM. This tunnel current now depends on the 
magnetic information and can be measured. However, this signal has to be separated from contributions of a varying tip-sample distance caused by the surface topography which is achieved in the following way. In order to filter out the magnetic information the polarization of the incoming laser light is modulated in its helicity, switching between lefthanded and right-handed circular polarization. The frequency of this modulation is higher than the feedback loop bandwidth $(2 \mathrm{kHz})$ and therefore causes an amplitude modulation of the tunnel current which is separated by a lock-in amplifier. The STM feedback loop maintains the average tunnel current reproducing the topography of the sample surface with very high accuracy. Accordingly, two contrast types are obtained simultaneously, first, the sample surface topography and second, the magnetic domain structure. Details of the electrical measurement scheme and modulation techniques can be found in former publications. ${ }^{3,4}$

For illumination of the sample, two different lasers were used, a single-mode HeNe laser (633 nm wavelength) and a diode-pumped, frequency-doubled Nd:YAG with $532 \mathrm{~nm}$ wavelength.

The microscope's imaging capability for topography and magnetic structure was demonstrated previously using red laser light $(633 \mathrm{~nm}$ wavelength) under ambient conditions and in external magnetic fields. ${ }^{6}$ The resolution in magnetic contrast estimated from the steepness of the contrast transitions at the edge of the magnetic domains was of the order of $250 \mathrm{~nm}$. The aim is to further improve the resolution for magnetic imaging which requires the detection of the light intensity more locally, that is to shrink the active volume of the GaAs tip which contributes photoexcited carriers to the tunnel current. This can be achieved in three different ways. First, a reduction of the carrier diffusion length would reduce the contribution of electrons generated outside the band bending region. This could be achieved by an increase of doping or impurity density reducing the carrier lifetime. Second, the focusing power of the depletion region originating from the nonplanarity of the band bending ${ }^{3,7}$ can be reduced using sharper tips requiring a more sophisticated tip production. The third possibility, exploited here, takes advantage of the strong wavelength dependence of the light penetration depth into the semiconductor. ${ }^{5}$ The relatively small decrease of the wavelength from 633 to $532 \mathrm{~nm}$ causes a reduction of the penetration depth into GaAs from 250 to $130 \mathrm{~nm}$. These three resolution limiting factors act cumulatively; an independent improvement of any factor will lead to an improved resolution.

Figure 1 shows $4 \times 2 \mu \mathrm{m}^{2}$ images of the MCD signal of the $\mathrm{Co} / \mathrm{Pt}$ multilayer taken in about $20 \mathrm{~min}$ time using respectively $633 \mathrm{~nm}$ [Fig. 1(a)] and $532 \mathrm{~nm}$ [Fig. 1(b)] laser light wavelength. Both images show the magnetic structure in form of bits having approximately $1 \mu \mathrm{m}$ diameter (the smaller structures are caused by surface irregularities which are also visible in the topography). Not only are the magnetic bits clearly resolved but also irregularities of their rim and some inner structure are visible. This fine structure can be reproducibly imaged and is independent from the scan direction used for imaging. Therefore, we conclude that these features represent deviations from a perfectly circular magnetic bit. The mere fact that this structure can be made visible transition than the 633 nm wavelength. Using the definition
Downloaded 26 Oct 2010 to 131.155 .110 .244 . Redistribution subject to AlP license or copyright; see http://apl.aip.org/about/rights_and_permissions

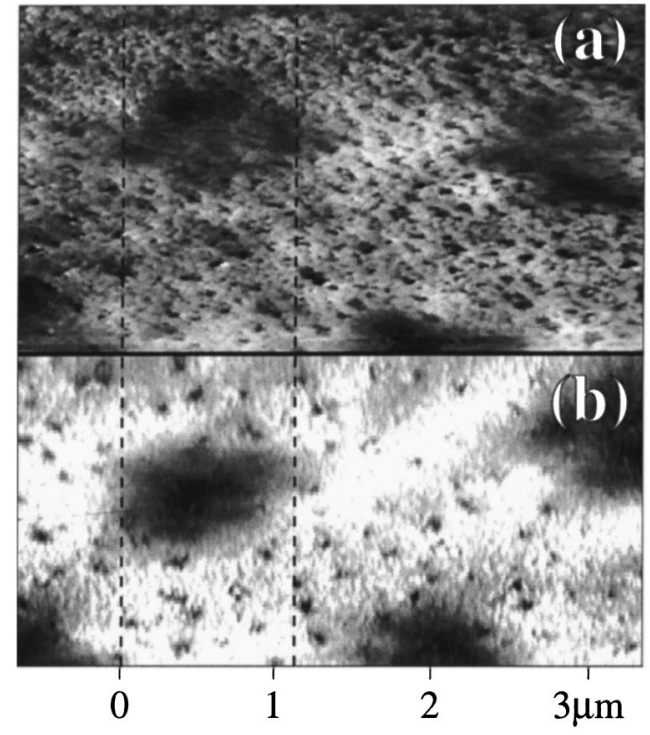

FIG. 1. Magnetic structure of a Co/Pt multilayer with prewritten domains (bits) imaged with the MONF STM. The laser excitation wavelength was (a) $633 \mathrm{~nm}$ and (b) $532 \mathrm{~nm}$. Visible are irregularly shaped bits with $1 \mu \mathrm{m}$ diameter and smaller structures caused by surface defects.

already suggests that the resolution must be much better than the size of the bits.

We will quantify the resolution using a definition which is based on the smallest resolvable magnetic stripe. Assuming a stripe with a magnetization opposite to that of its surrounding (corresponding to signal level " 0 " inside and " 1 ", outside with sharp transitions at the edges), the finite resolution of the microscope would blunt these transitions. The overlap of the two transitions will result in a nonzero signal level in the center of the stripe. We define the resolution of the microscope as the stripe width such that this signal level at the center drops to $1 / 2 .{ }^{8}$ The next step is to extract the transition width of the magnetic edge from the experimental data. In a simple approach to our experimental situation, we model the tip as a circularly shaped detector which is crossing a magnetization transition. This would result in a response function as shown in Fig. 2 (line 1). A more realistic approach is taking into account the decay length $\lambda$ of the excited electrons meaning that electrons excited at the center give a full contribution while the influence of electrons excited further away decays with $\exp (-R / \lambda)$, where $R$ is the distance to the tip center, corresponding to $\int_{x=x_{0}}^{\infty} \int_{y=-\infty}^{\infty} e^{-R / \lambda} d x d y$ (curve 2 in Fig. 2). A convenient circumstance is that phenomenologically, such a transition can also be described by a function $[\exp (x / w)+1]^{-1}$ (similar to the Fermi-Dirac distribution function; Fig. 2, line 3) which is, within the noise level of experimental data, identical with the refined model function (line 2). For ease of computation, we evaluated the transition sharpness of the bit edges using the Fermi-Dirac function. We estimated the resolution for the two graphs shown in Fig. 1 by analysis of radial line scans starting from the bit center and crossing the bit edges. Examples of the cross section of the magnetization transitions (averaged over five lines) are shown in Fig. 3 for the two wavelengths used together with their best fits. Clearly, the $532 \mathrm{~nm}$ wavelength produces a much sharper 


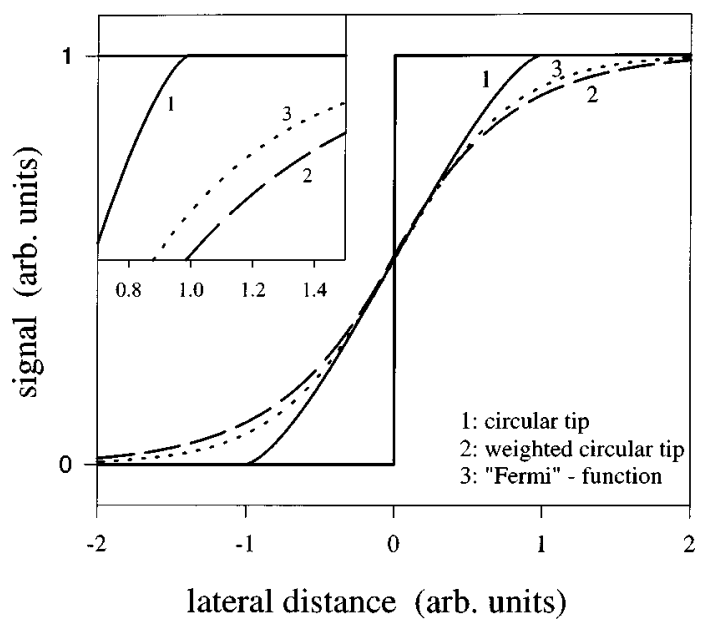

FIG. 2. Schematic drawing of model functions describing the softening of the sharp transition (full line) between signal level 0 and 1 . The dotted line (1) is obtained for a circular tip of radius 1 passing over the step function. The dashed line (2) is obtained for a circular tip with enhanced sensitivity of the center. The dash-dotted line (3) is a Fermi distribution function type fitted to line 2. The inset shows details of the curves around the onset of the softened transition.

for the resolution given above we find a resolution of (240 $\pm 65) \mathrm{nm}$ for the $633 \mathrm{~nm}$ wavelength compared to (60 $\pm 35) \mathrm{nm}$ for $532 \mathrm{~nm}$ wavelength of the laser light, i.e., an improvement of a factor of 4 . Within the error this is compatible with the factor of 2 , one would expect from the wavelength dependence of the light penetration depth, although it seems to be higher. The reason therefore might be found in the complicated electron focusing properties of the band bending region of the semiconductor which depends on the

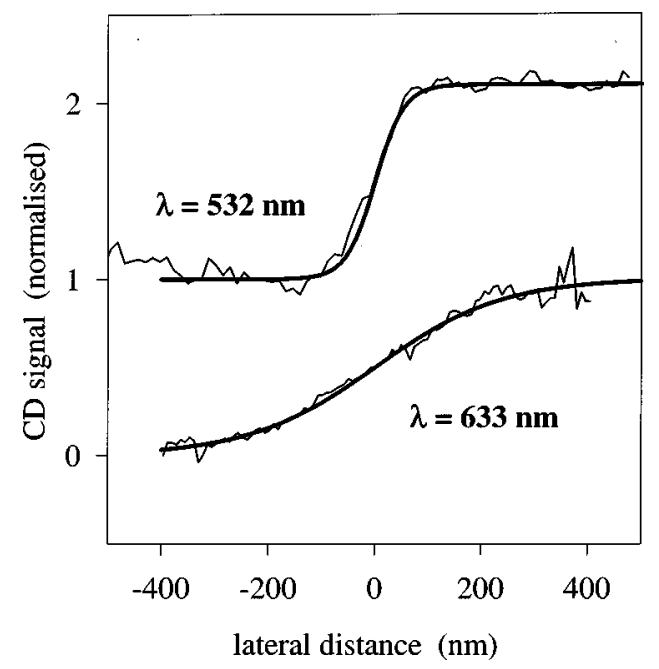

FIG. 3. Normalized MCD signal at the edges of the bits shown in Fig. 1 for the two different wavelengths used. The measured curves (thin lines) are averaged over five line scans. Shown are best fits using the Fermi function (thick lines). actual tip geometry. ${ }^{3}$ The spatial distribution of the near-field (NF) strength which will depend on both the tip-sample geometry and the laser light wavelength also might affect the resolution. However, these contributions cannot be quantified without knowing the exact experimental geometry in the $\mathrm{NF}$ regime. Complications arising from distortions of the light polarization in the NF regime are not important in our case because we do not analyze the polarization of the transmitted light.

Using a GaAs semiconductor tip as a local photodetector in a magneto-optical near-field STM, we have shown how a reduction of the excitation wavelength and the resulting reduced penetration depth results in a considerable improvement of the resolution in magnetic imaging. A further wavelength reduction, however, is impeded by the nonavailability of a short-wavelength laser source with sufficient stability. Future resolution improvement will have to act on the electric parameters of the semiconductor tip. First, by a reduction of the carrier diffusion length (higher doping density, or a different semiconductor material) and second, by a reduction of the focusing properties of the depletion field (forward bias operation, or a sharper tip). A resulting reduction of detectable photocarrier current has to be compensated for by increasing the optical power. Assuming realistic operation parameters for the microscope, an optimized collection volume of the photocarriers should result in a magnetic resolution of $6 \mathrm{~nm}$. An advantage of the above-presented technique is that simultaneously magnetic information as well as highresolution topographic information is extracted. Moreover, since the probe is nonmagnetic, soft magnetic samples can be studied also upon application of an external magnetic field.

The authors acknowledge the technical support of A. F. van Etteger, J. Hermsen, and J. Gerritsen. They thank A. van Geelen and G. J. Bauhuis for supplying and characterizing the semiconductor material. Part of this work was supported by the Stichting Fundamenteel Onderzoek der Materie (FOM) and by a fellowship (RHMG) of the Royal Netherlands Academy of Arts and Sciences (KNAW).

\footnotetext{
${ }^{1}$ For a review on MFM, see Scanning Tunneling Microscopy II, edited by R. Wiesendanger and H.-J. Güntherodt, Springer Series in Surface Sciences 28 (Springer, Berlin, 1992), p. 151.

${ }^{2}$ E. Betzig, J. K. Trautman, R. Wolfe, E. M. Gyorgy, P. L. Finn, M. H. Kryder, and C.-H. Chang, Appl. Phys. Lett. 61, 142 (1992).

${ }^{3}$ M. W. J. Prins, R. Jansen, R. H. M. Groeneveld, A. P. van Gelder, and H. van Kempen, Phys. Rev. B 53, 8090 (1996).

${ }^{4}$ M. W. J. Prins, R. H. M. Groeneveld, D. L. Abraham, and H. van Kempen, Appl. Phys. Lett. 66, 1141 (1995).

${ }^{5}$ D. E. Aspnes and A. A. Studna, Phys. Rev. B 27, 985 (1983).

${ }^{6}$ M. W. J. Prins, M. C. M. M. van der Wielen, D. L. Abraham, H. van Kempen, and H. W. van Kesteren, IEEE Trans. Magn. 30, 4491 (1994).

${ }^{7}$ M. W. J. Prins and A. P. van Gelder, Physica (Utrecht) 218, 297 (1996).

${ }^{8}$ The Rayleigh criterion for resolving two overlapping functions is less strict and thus will result in smaller values of the resolution. The signalto-noise ratio of our experimental data, however, does not allow the application of this criterion.
} 